\title{
Establishing reconstructive neurosurgery as a subspecialty
}

\author{
Justin M. Brown, MD, ${ }^{1}$ Mark A. Mahan, MD, ${ }^{2}$ Ross Mandeville, MD, ${ }^{3}$ and Bob S. Carter, MD, PhD ${ }^{4}$ \\ Departments of ${ }^{1}$ Neurosurgery and ${ }^{3}$ Neurosciences, University of California, San Diego, California; ${ }^{2}$ Department of \\ Neurosurgery, Clinical Neurosciences Center, University of Utah, Salt Lake City, Utah; and ${ }^{4}$ Department of Neurosurgery, \\ Massachusetts General Hospital, Boston, Massachusetts
}

\begin{abstract}
Neurosurgery is experiencing the emergence of a new subspecialty focused on function restoration. New, evolving, and reappraised surgical procedures have provided an opportunity to restore function to many patients with previously undertreated disorders. Candidates for reconstruction were previously limited to those with peripheral nerve and brachial plexus injuries, but this has been expanded to include stroke, spinal cord injury, and a host of other paralyzing disorders affecting both upper and lower motor neurons. Similar to the recent evolution of the well-established subdisciplines of spinal and vascular neurosurgery, reconstructive neurosurgery requires the adaptation of techniques and skills that were not traditionally a part of neurosurgical training. Neurosurgeons-as the specialists who already manage this patient population and possess the requisite surgical skills to master the required techniques-have a unique opportunity to lead the development of this field. The full development of this subspecialty will lay the foundation for the subsequent addition of emerging treatments, such as neuroprosthetics and stem cell-based interventions. As such, reconstructive neurosurgery represents an important aspect of neurosurgical training that can ameliorate many of the deficits encountered in the traditional practice of neurosurgery.
\end{abstract}

https://thejns.org/doi/abs/10.3171/2017.5.FOCUS17102

KEY WORDS nerve transfer; tendon transfer; electrodiagnostics; free functional muscle transplant; peripheral nerve surgery; spinal cord injury; stroke; brachial plexus injury; reconstructive neurosurgery

A s the establishment of neurosurgical subspecialties has become increasingly refined, it has become apparent that we have been left with a hole in patient care. The subspecialties, as they now exist within neurosurgery, include pediatric, vascular, oncologic, spinal, functional, peripheral nerve, trauma/critical care, and skull base neurosurgery (http://www.societyns.org/fellowships/ index.asp). Each of these specialties encounters disorders that result in motor impairment, and each has a procedure (or more) that aids in the recovery of such impairments. Such procedures, though, are typically only available in the acute period after the impairment is realized. Decompressing a nerve root in a patient who presents with foot drop, resecting a tumor that is abutting the motor strip or compressing the spinal cord, and reconstructing a severed peripheral nerve all have their roles in functional restoration. Within neurosurgery, only peripheral nerve and functional neurosurgery have procedures that may provide benefits in the subacute or even chronic stage in such patients. Even in these subspecialties, a paralysis reversal procedure is typically the exception rather than the rule.

Peripheral nerve surgeons are often considered the "paralysis experts" in a multidisciplinary neurosurgical practice. That being the case, most peripheral nerve neurosurgical practices predominantly treat compressive neuropathies, nerve tumors, and peripheral nerve sources of pain, with paralyzing nerve injuries comprising the minority of the presenting conditions. Admittedly, some centers do have specialists who treat a preponderance of patients with paralyzing injuries. However, the paralyzing injuries that these practitioners treat are not common entities and thus these tend to be served by niche practices. Among paralyzing injuries, the greatest reconstructive challenge for peripheral nerve surgeons is a complete brachial plexus injury with a flail arm. ${ }^{23}$ While a few high-volume centers may operate weekly on such patients, most medical centers with such specialists see at most a handful of cases per year.

ABBREVIATIONS AFO = ankle-foot orthosis; ASIA = American Spinal Injury Association; $\mathrm{AVM}=$ arteriovenous malformation; $\mathrm{CMAP}=$ compound motor action potential EMG = electromyography; LMN = lower motor neuron; UMN = upper motor neuron; $\mathrm{SCI}=$ spinal cord injury; $\mathrm{TBI}=$ traumatic brain injury.

SUBMITTED March 1, 2017. ACCEPTED May 9, 2017. 
Statistically, brachial plexus injuries that require surgery have been found to occur in the range of 2 injuries per 1 million persons annually. ${ }^{25}$ Of those, almost $75 \%$ are upper plexus injuries that involve relatively straightforward management. The remaining $25 \%$, or roughly 0.5 injuries per 1 million persons, comprise the flail limb cases that are notably more complex to adequately reconstruct, making it unreasonable to imagine that every center will have a team with the requisite expertise in this entity. Additionally, the optimal management of these injuries often involves procedures that fall outside of the typical expertise of a peripheral nerve neurosurgical specialist. As a result, there are a number of clinicians treating these injuries on an infrequent basis and without the full armamentarium of applicable surgical procedures at their disposal.

It is becoming well established in the literature that high-volume centers of any given pathology tend to have better outcomes and fewer complications than lower volume centers. ${ }^{34,35,46}$ While this does speak directly to both surgical decision-making and surgical skill, we would suggest that this can also be extrapolated to ancillary services such as electrodiagnostic skills, the quality of the peripheral nerve imaging available, intraoperative neurophysiological capabilities, and the associated rehabilitation programs, to name a few.

\section{Potential Patients for Reconstructive Surgery}

When considering paralysis from any cause, there is a substantial number of patients who are largely neglected in reconstructive surgery. As in the example noted above, there are about 2 surgical brachial plexus injuries per 1 million persons annually, but there are around 10-fold more cervical spinal cord injuries (SCIs) that would benefit from arm and hand reanimation. ${ }^{7}$ Even these are still niche populations in comparison with the massive numbers of patients who annually present at any given medical center for other sources of weakness and paralysis. In comparison with the 11,000 new annual SCIs in the US, ${ }^{50}$ there are more than 600,000 new strokes. Roughly $80 \%$ of these strokes result in some degree of hemiparesis that is amenable to surgical correction. ${ }^{29}$ Additionally, there are 1.7 million new traumatic brain injuries (TBI), and an estimated $15 \%$ of these result in hemiparesis and $6 \%$ result in quadriparesis, ${ }^{24}$ translating into roughly another 300,000 surgical candidates. When considering cerebral palsy, multiple sclerosis, and spina bifida, the number of paresis and paralysis cases that are potentially amenable to surgical amelioration becomes staggering. This does not take into account the numerous cases of weakness from degenerative spinal disorders, iatrogenic nerve injuries, motor control impairments from curative brain or spinal cord tumor resections, etc.

The vast majority of patients with these numerous causes of paralysis are never offered the procedures that would ameliorate their condition. Typically, if interventions are offered, they are offered by nonsurgical providers and are of transient benefit, such as aggressive bracing regimens and multiple rounds of botulinum toxin therapy. In fact, there appears to remain a general ignorance of the available surgical options at many major medical centers across the US, perhaps in large part because there are few surgeons with the appropriate skill set and interest. With these statistics alone, it is clear that such a specialist would have more than enough cases from a single hospital to keep busy full time, simply from performing paralysis-reversing reconstructive procedures. The surgical procedures referred to above, which apply to complete brachial plexus injuries, have broad application across each of these disorders, as would the associated services including neurophysiology, imaging, rehabilitation, and orthotics (Table 1).

Neurosurgeons have often been at the forefront of basic research into future modalities for functional restoration in the setting of neurological injury, and appropriately so. Such modalities include stem cell-based therapies and other biological interventions that encourage CNS regeneration. ${ }^{13,32,38,45}$ Similarly, our advances in neuromodulation and neuroprosthetics have been significant in recent years. ${ }^{36,39,49}$ Even now, some options for severe injuries are emerging as promising treatments. However, as we delve into these new arenas, what is frequently missing is an understanding of the current clinical "state of the art" in paralysis reversal, which is necessary so that we can understand where readily available options end and where future interventions would be best implemented.

\section{Clinical Approach to Paralysis Reversal}

The first critical step in devising a reconstructive strategy is to determine the source and primary type of paralysis. The source refers to the causative lesion. It is essential to first determine if it has been fully addressed or has the potential to progress with time. An incomplete foot drop, for example, might be best addressed (sometimes even in the subacute or chronic stage) by revising a prior spinal nerve root decompression..$^{20,21}$ The reasons for this are twofold. First, occasionally there is the opportunity to treat the pathophysiology directly, thereby reversing the latent neurapraxia and achieving spontaneous recovery of function as a result. In this uncommon scenario, the original reconstructive plan is then altered. Second, and of greater interest, is that when the causative lesion is neglected the reconstructive strategy may fail because the deficit later progresses and, for example, the transferred nerve or muscle subsequently also loses strength. This concept applies to incompletely decompressed nerve roots following spine surgery as described above, delayed hydrocephalus or shunt failure following TBI, regrowth of incomplete tumor resections, or even the development of a spinal cord syrinx following SCI.

\section{Lower Motor Neuron Injuries}

Once we establish the stability of the source, we need to determine whether the predominant type of weakness is of upper motor neuron (UMN) or lower motor neuron (LMN) origin. This is critical, as these types of paralysis are managed very differently. In managing LMN disorders, a determination must be made as to whether the impairment is neurapraxic or axonotmetic. In a neurapraxic injury, where axonal continuity is preserved (as in the foot drop example mentioned above), we can at times effective- 


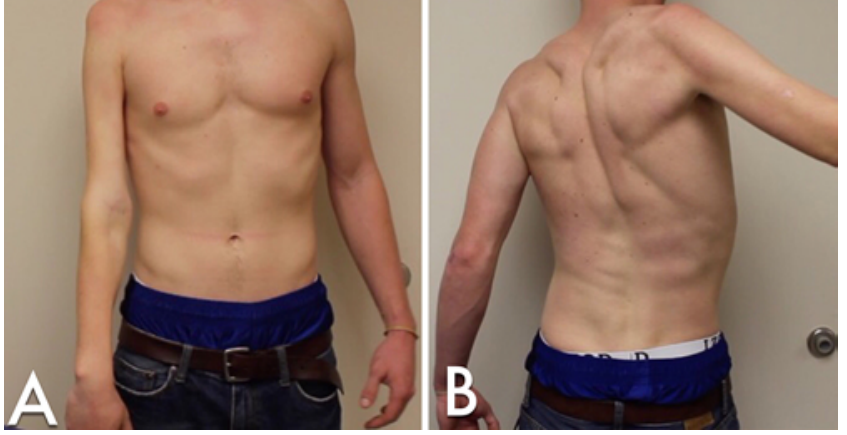

FIG. 1. Case 1. A brachial plexus injury primarily affecting the posterior cord and musculocutaneous nerves is shown with atrophy and paralysis of the deltoid, biceps, triceps, and wrist and finger extensors.

ly decompress the nerve and the restoration of function will ensue as remyelination progresses. ${ }^{2,44,51}$ Alternatively, if those axons are predominantly severed, the function of the original muscles can only be restored by the regrowth of the axons back to those denervated muscles. It is essential to understand that there is a time window within which reinnervation must be established. There are 2 primary strategies for restoring innervation. Anatomical reconstructions (using grafts to reconstruct the originally damaged nerves) are favored when they appear likely to restore function effectively and in a timely fashion. When alternative axon sources appear to offer more rapid and robust reinnervation, nerve transfer often becomes a better choice. ${ }^{6}$ When choosing among potential nerve transfers, we are careful to avoid causing a new deficit. Therefore, selection is between a fascicle of another nerve, thus preserving the donor nerve's primary function, or using the entire nerve branch if we confirm there is another intact muscle that is redundant in function to the one being transferred. When selecting between these strategies, considerations include the number of axons available from the source nerve, the distance to the reinnervation target, and whether the source is functionally synergistic. ${ }^{6}$ If excessive time has transpired and this window closes, effective reinnervation may be precluded and other strategies must be sought to approximate the lost function. See Illustrative Case 1.

\section{Illustrative Case 1: Nerve Transfers in Brachial Plexus Injury}

A 21-year-old male patient presented following a motorcycle accident that resulted in injuries to the musculocutaneous nerve and posterior cord of the brachial plexus (Fig. 1). He underwent fascicular transfers from the median and ulnar nerves to the musculocutaneous nerve branches that innervate the biceps and brachialis muscles, as well as transfer of the lower subscapular nerve to the long head of the triceps branch of the radial nerve. He recovered good strength in both of these muscle groups with antigravity function at 3 months and on to an essentially full recovery by 1 year (Fig. 2). See Video 1 .

VIDEO 1. Case 1. Restoration of function to the biceps and brachialis muscles from axons that originally contributed to median and ulnar nerve function in wrist and finger flexion is demonstrated. The patient recovered muscle bulk, tone, and strength. Movement has also become intuitive and does not require "trick maneuvers" of the
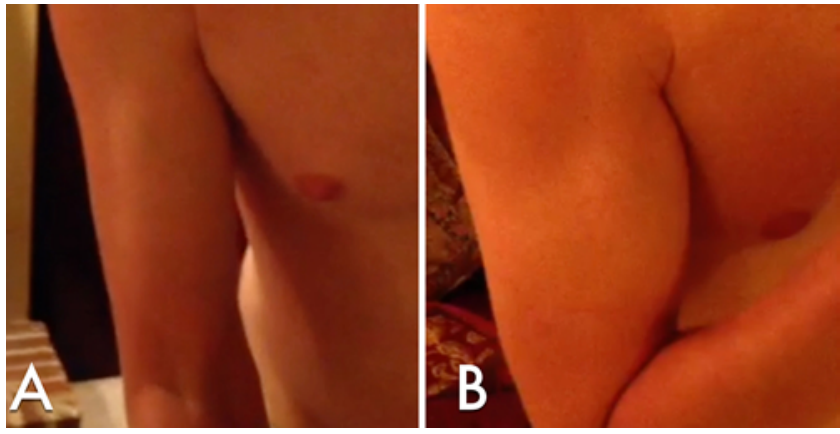

FIG. 2. Case 1. Restoration of function to these muscles is shown with normal bulk and good strength in the biceps muscle after reinnervation with axons originally destined for the wrist and hand.

wrist or hand to activate. Copyright Justin Brown. Published with permission. Click here to view.

What is commonly overlooked is that LMN injuries are not confined to extravertebral peripheral nerve pathology, as in the cases above. In fact, thoracolumbar spinal injuries are predominantly LMN in nature. Even cervical SCIs typically result in a significant amount of LMN damage at the site of trauma because the alpha motor neurons themselves are destroyed and their associated axons therefore degenerate (Fig. 3). ${ }^{5}$ This also occurs with brainstem pathology that affects the facial nucleus, for example. These injuries, when recognized appropriately, are also amenable to the previously discussed interventions. Likewise, when sufficient time has passed, alternative methods must be employed because the original muscle and nerve are no longer amenable to receiving axons and recovering function. The alternative methods most commonly involve tendon transfer or muscle transplant. See Illustrative Case 2.

\section{Illustrative Case 2: Muscle Transfers for an LMN Injury With a Central Source}

A 22-year-old female patient presented with history of a Chiari malformation and an associated syrinx. She underwent decompression, but the cyst continued to expand, and she experienced progressive weakness in her arms. She then underwent shunting of the syrinx, and her motor status stabilized. Two years later, her bilateral biceps strength remained at Grade 2/5 (Fig. 4). Electrodiagnostics determined that her strongest local muscle group was the latissimus muscles bilaterally. She underwent bipedicle transfer of the bilateral latissimus muscles to reconstruct elbow flexion with good recovery of Grade $4 / 5$ elbow flexion strength bilaterally (Fig. 5). See Video 2.

VIDEO 2. Case 2. After 2 years of ineffective elbow flexion, the patient had this function restored through the use of bilateral transferred latissimus dorsi muscles. She is now able to transfer a heavy purse between her arms and accomplish tasks that she had been unable to perform previously. Copyright Justin Brown. Published with permission. Click here to view.

\section{Upper Motor Neuron Injuries}

In contrast to LMN injuries, when the injury is predominantly of a UMN source, reconstruction is undertaken after a significant delay following injury. Because CNS plasticity frequently achieves impressive rewiring, particularly in the context of appropriate therapy, it is imperative 
to remain patient and allow for such spontaneous recovery over at least 6-12 months. ${ }^{14,27,28}$ When a functional plateau has been reached, there are a number of interventions that may optimize the new functional status. Prior to proceeding, it is important to ensure that the patient has received appropriate therapy and has been compliant with that therapy.

Recent advances in the implementation of nerve transfer surgery have laid the groundwork for peripheral nerve surgeons to venture outside of peripheral nerve paralysis sources to CNS sources that result in similar deficits. Addressing cervical SCI with nerve transfers was found to be a natural extension of the strategies for restoring lower brachial plexus injuries where the C7-T1 nerve roots are lost. ${ }^{3,4,8,19}$ The deficits encountered in each of these injuries are essentially identical. In both cases, there is loss of control of the hands and triceps. However, in brachial plexus injuries, the LMNs are lost. In cervical SCI, LMNs often remain, just without connecting to the UMNs (Fig. 3). The loss of UMN input leads to another problem-spasticity. The problem of focal spasticity has led to renewed enthu- siasm for a procedure that has been commonly reported on in the functional neurosurgery literature-selective peripheral neurotomy. ${ }^{33,40,42,43}$ Peripheral nerve surgeons have been quick to adopt this procedure, as it involves anatomy with which they are already quite familiar. See Illustrative Cases 3 and 4.

\section{Illustrative Case 3: Nerve Transfers for UMN Paralysis in SCI}

A 30-year-old female patient presented 3 years after a fall down a staircase that resulted in a C-5, American Spinal Injury Association (ASIA) Impairment Scale Grade A SCI. As is typical for a C-5 injury, she was found to have good control of the external rotators of her shoulder but with paralyzed yet innervated triceps as determined by electrodiagnostic studies. Three years following her injury, she underwent an axillary-to-radial nerve transfer using the teres minor branch of the axillary nerve to reinnervate the triceps branch of the radial nerve. By 12 months after the surgery, she had recovered Grade 4/5 strength in her triceps (Fig. 6). She secondarily underwent transfer of the brachialis branch of the musculocutaneous nerve via

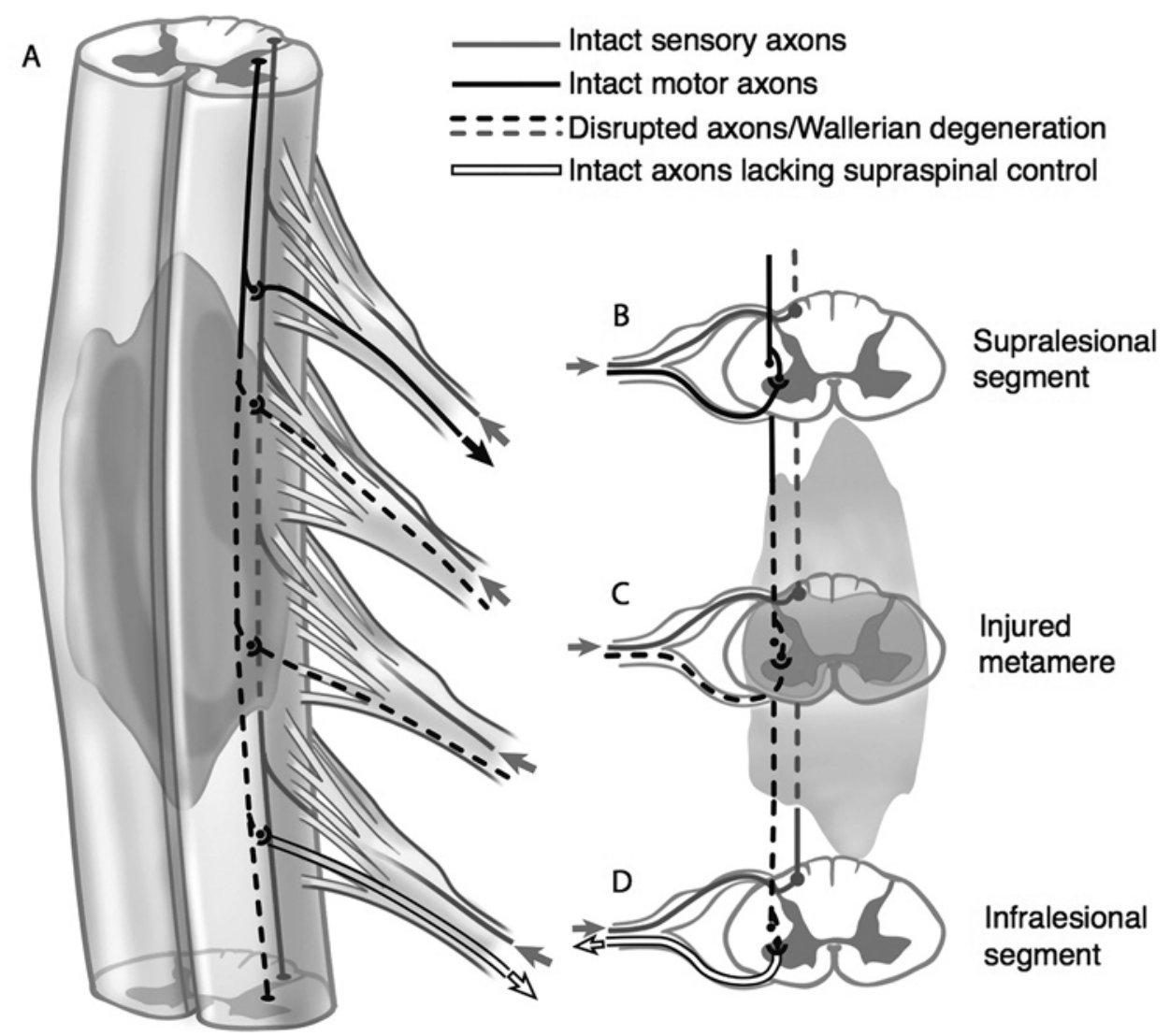

FIG. 3. CNS injuries often present with aspects of both UMN and LMN injuries. A: At the region of the impacted spinal cord there is damage to both the traversing white matter tracts and central gray matter. The spinal cord caudal to this injury is essentially normal $(B)$, while the cord at the level of impact shows injury to its gray matter and associated motoneurons (C). When these are injured, their peripheral axons degenerate in a similar manner as a peripheral nerve injury. D: The spinal cord below the injury has healthy gray matter with normal axons emanating from the cord. However, these motoneurons are deprived of supraspinal input because of disruption of the white matter tracts rostral to this site and thus remain without function. Such nerves are amenable to reinnervation, even years after such an injury. From Brown JM: The reconstructive neurosurgery of spinal cord injury, in Dimitrijevic MR, Kakulas BA, McKay WB, Vrbova G (eds): Restorative Neurology of Spinal Cord Injury. 2012, p 134, reproduced by permission of Oxford University Press (http://global.oup.com/academic/product/restorative-neurology-of-spinal-cord-injury9780199746507). 


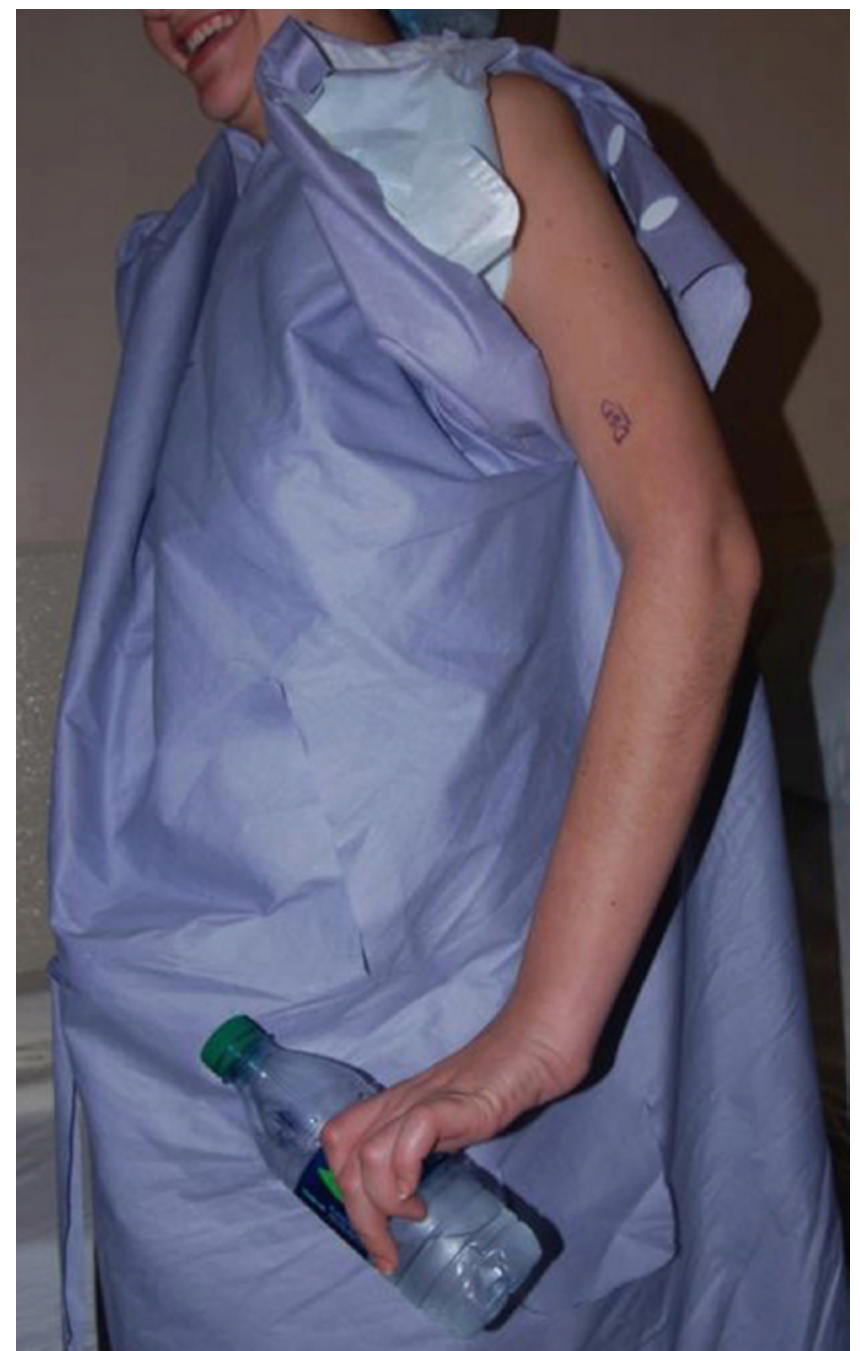

FIG. 4. Case 2. Progressive loss of motor nuclei resulted in Grade $2 / 5$ strength in the patient's biceps bilaterally. While there was a perceptible contraction, she was not able to break gravity and use her arms in a useful way as a result of this severe and chronic weakness.

a sural graft to the anterior interosseous nerve. Roughly 9 months following this intervention, she recovered active finger flexion (Fig. 7). See Video 3.

VIDEO 3. Case 3. This case illustrates the opportunity afforded to patients with $\mathrm{SCl}$ of primarily UMN injury. Because the paralyzed muscle groups maintain their LMN (see Fig. 3), they can receive axons even years following the onset of UMN paralysis. She regained effective antigravity triceps function and a full grasp, which dramatically enhanced her quality of life. Copyright Justin Brown.

Published with permission. Click here to view.

Illustrative Case 4: Selective Peripheral Neurotomy for SCl-Related Spasticity

A 53-year-old male patient was in a dirt bike accident and suffered an upper cervical fracture dislocation resulting in a C-4 ASIA Grade D SCI . He was stabilized and recovered significant strength, but persistent left-side spasticity severely limited his function. In particular, he could not reach his mouth with his functional biceps as a result of the severe spasticity of his triceps. He underwent neu-
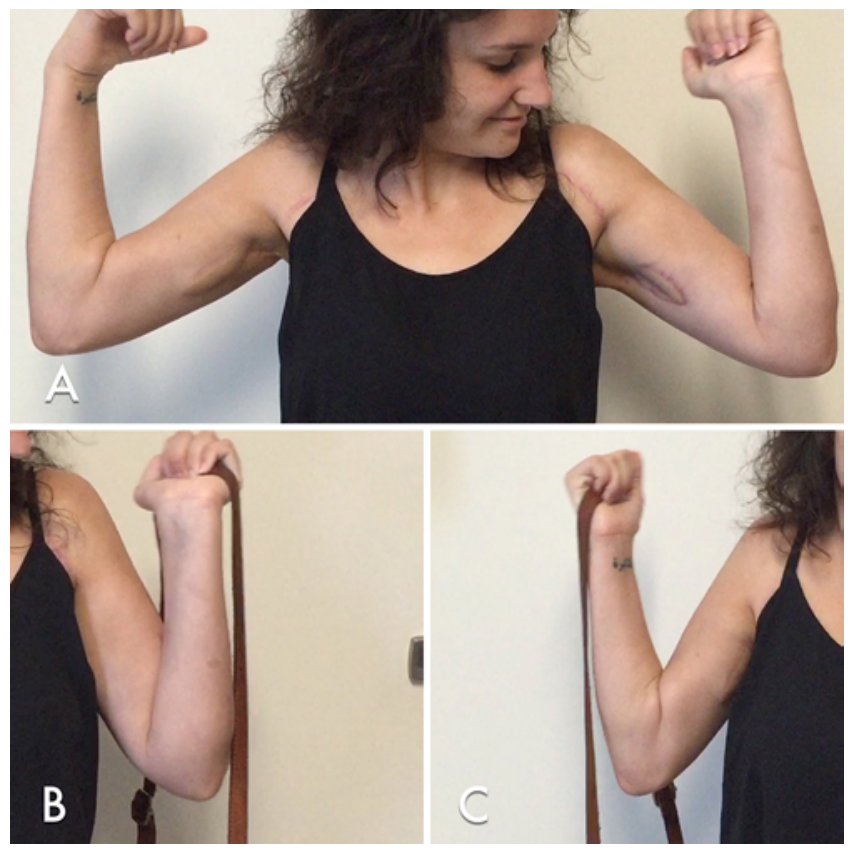

FIG. 5. Case 2. After transfer of the bilateral latissimus doors muscles and retraining for several months, the patient developed effective use of her new elbow flexors. A: The patient is seen simply flexing the muscles. B: The patient curling her large and full purse with her left arm. C: The patient demonstrating a similar level of strength and function in her right arm.

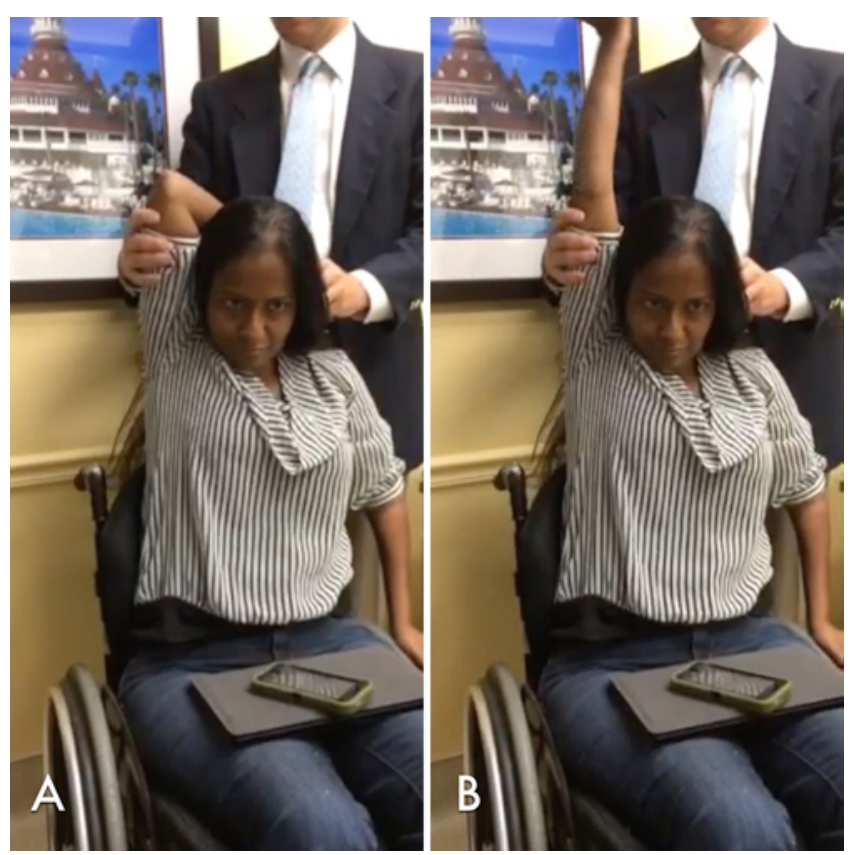

FIG. 6. Case 3. Several years after the patient's cervical SCI, she underwent nerve transfers from the teres minor branch of the axillary nerve to the triceps branch of the radial nerve. Because her injury was primarily UMN, the window for reinnervation persists and late nerve transfers are still effective. She achieved full range of motion by raising her arm overhead by 1 year following the surgery. 

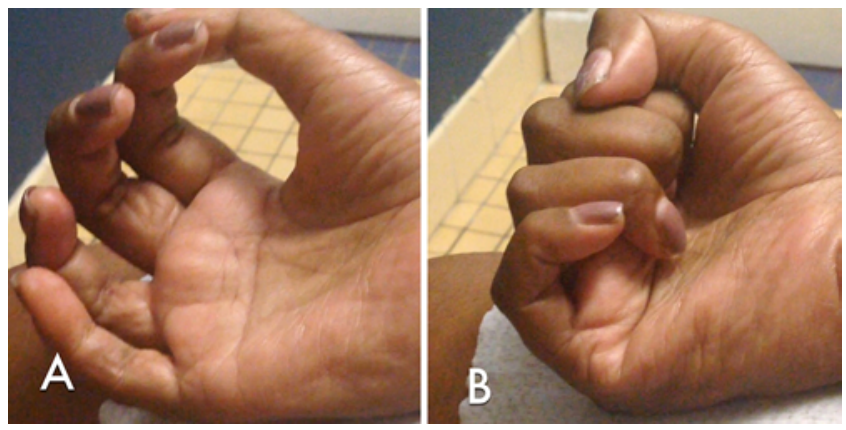

FIG. 7. Case 3. The finger flexors were reinnervated with a 2-step intervention. In the first step, which was done at the time of the triceps nerve transfer, a sural graft was connected to the brachialis branch of the musculocutaneous nerve. In the second step, which was performed many months later, the distal end of this graft was connected to the anterior interosseous nerve to recover finger flexion. Another 9 months transpired before the patient realized new finger flexion-the first time she had moved her fingers since her injury.

rotomy of the radial nerve branches to the triceps, effectively eliminating four-fifths of the branches to each head of the triceps. Postoperatively, he was immediately able to reach his mouth, and over the next 3 months he regained near-normal control of his triceps (Fig. 8). See Video 4.

VIDEO 4. Case 4. Spasticity in large muscles like the triceps is often not effectively reduced with botulinum toxin administration. This patient was initially unable to reach his mouth with significant effort. After neurotomy of the triceps branches, he rapidly recovered this function. Copyright Justin Brown. Published with permission. Click here to view.

\section{Incorporating Non-Nerve-Based Reconstructive Procedures}

Without the additional procedures more typically undertaken by plastic or orthopedic surgeons, our reconstructive repertoire is limited. Having nerve-based procedures alone in our armamentarium often leads to a myopic view of reconstructive options: if a nerve transfer will not accomplish the needed function restoration, the patient is either "out of luck" or maybe there is a surgeon in another specialty who can tackle the case.

This situation is reminiscent of the recent history of both vascular and spinal neurosurgery. It was not long ago when our treatment of cerebral aneurysms was limited to craniotomies with clip application. When it became clear that a given lesion might be readily addressed via an endovascular approach, neurosurgeons had to rely on our radiologist colleagues. When neurosurgeons adopted that skill set, we advanced vascular neurosurgery tremendously. ${ }^{11,22}$ Similarly, less than 20 years ago, neurosurgeons commonly approached complex spine cases with an orthopedist colleague. In this scenario, the neurosurgeon would address the neurological aspect of the intervention and then call for orthopedist colleagues to instrument and stabilize the spine. This deficit limited neurosurgery's role in even basic degenerative cases. Such a handicap at times resulted in significant intervention bias and taking stability risks. Once that skill set and accompanying understanding of spinal biomechanics were adopted by neurosurgeons, we evolved in our management of all forms of spinal pathol-

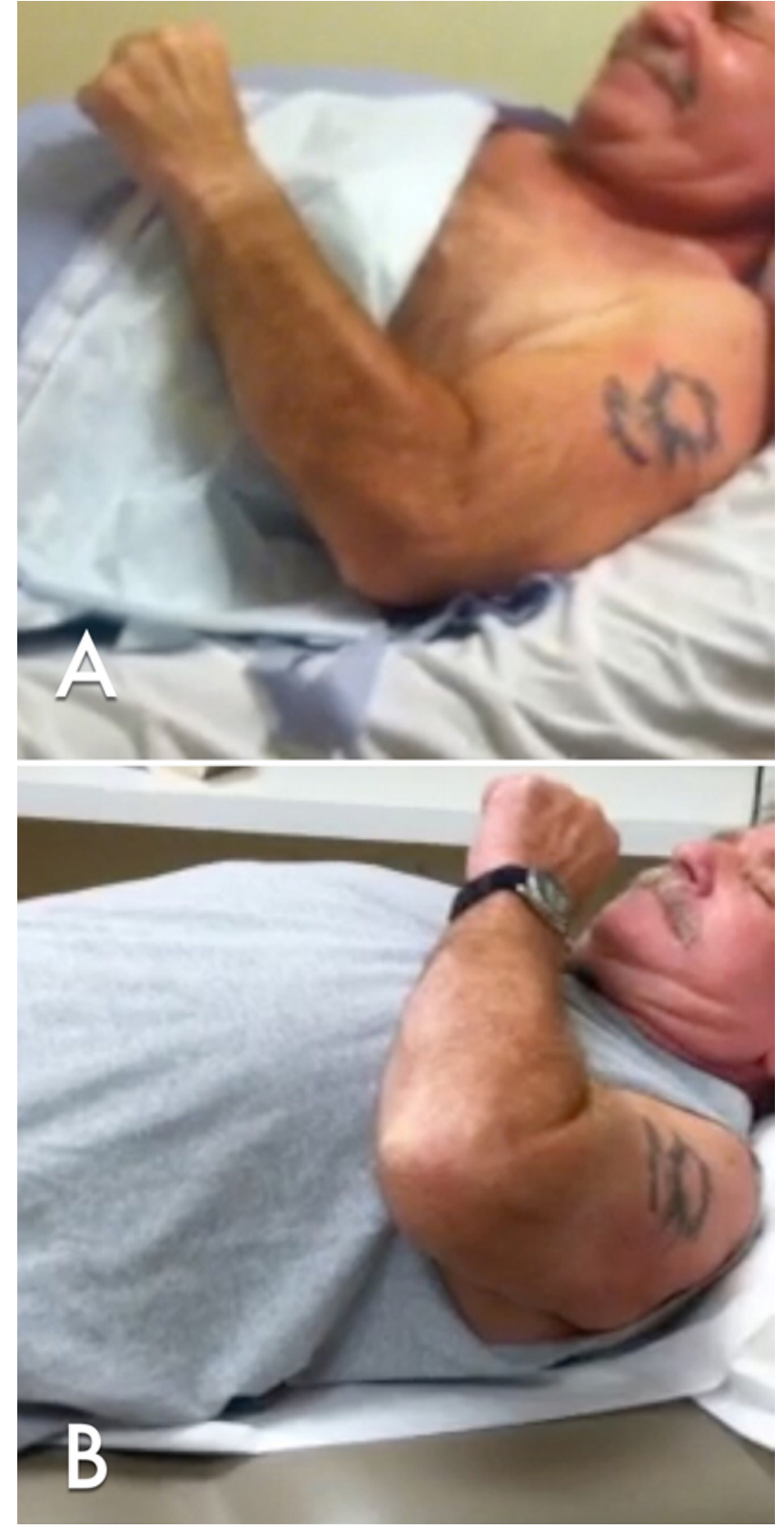

FIG. 8. Case 4. Following an incomplete SCI with good recovery of function, this patient remained with notable impairments due to high left-side spasticity in comparison with the right side. A: His ability to reach his mouth was impaired due to spasticity of the triceps. B: After selective peripheral neurotomy of the branches to all 3 heads of the triceps, he rapidly recovered his ability to reach his mouth and it persisted.

ogy-from the better appreciation of deformity in singlelevel spondylolisthesis to complex tumor resections.

Currently, peripheral nerve neurosurgeons employ the same approach as the spine neurosurgeons of a generation ago. We offer nerve grafting and transfers to those who we believe are candidates, but when tendon transfers or other options may be superior, we frequently refer patients to others with the hope that they have both the requisite expertise and share our passion to provide the best care possible to our patients. 
It is a common misconception that hand surgeons or foot and ankle surgeons are generally masters of the reconstructive methods available to these patients. Many of the procedures required are not the "bread and butter" of such practices. Instead, there tend to be centers that have expertise in these procedures, but usually in relation only to a particular disease entity. It is often not realistic to assume that if our nerve transfers fail (or are not an option), there will be a surgeon at the same hospital with the requisite skills to undertake what typically amounts to a rare tendon transfer.

\section{The Paralysis Center Concept}

While the concepts of function restoration are quite similar across pathologies, tackling all sources of paralysis at a single center has not been a common undertaking. While there are centers of excellence for brachial plexus reconstruction, for example, these same teams do not routinely treat patients with brain- or spinal cord-related paralysis. Likewise, centers well known for restoration of hand function following cervical SCI do not treat brain- or peripheral nerve-related paralyses. Centers tend to focus on a subset of procedures, a body region (e.g., upper vs lower extremity), and pathology type (brachial plexus vs spinal cord vs hemiplegia).

As noted above, the application of nerve transfers to SCI has begun to bring this patient population into the care of peripheral nerve neurosurgeons, but with it has come an additional impetus for adopting skills beyond nerve repair. Tetraplegia hand reconstruction was formerly limited to tendon transfers. Thus, only patients with at least 1 functional musculotendinous unit below the elbow were eligible for hand reanimation. With nerve transfers, this limitation no longer applies. Even when nerve transfers offer superior reconstruction, they are typically best applied with concomitant tendon and/or bony work to achieve optimal results. The "hybrid" reconstruction often yields the best results. See Illustrative Case 5.

\section{Illustrative Case 5: Combined Nerve and Tendon Interventions} for $\mathrm{SCl}$

A 33-year-old male patient suffered a midcervical fracture during a high school football game, leaving him with a C-5 ASIA Grade A SCI. He presented 12 years after his injury and was found on examination to have strong elbow flexion (which included a functional brachioradialis muscle) and weak wrist extension. However, his fingers exhibited no active flexion or extension. Electrodiagnostic studies demonstrated his candidacy for nerve transfers, except that the ulnar-side finger extensors had suffered some denervation. He underwent supinator branch of the radial nerve to posterior interosseous nerve transfer and brachialis branch of the musculocutaneous nerve transfer, via a graft to the anterior interosseous nerve. He additionally underwent thumb fusion to position it in both supination and palmar opposition, and finally a brachioradialis to flexor pollicis longus tendon transfer, giving him independence of thumb flexion in comparison with nerve transferdriven finger flexion. The combination of these procedures achieved active finger opening of the radial digits more than ulnar, as well as finger and thumb active flexion. The result was very functional (Fig. 9). See Video 5.
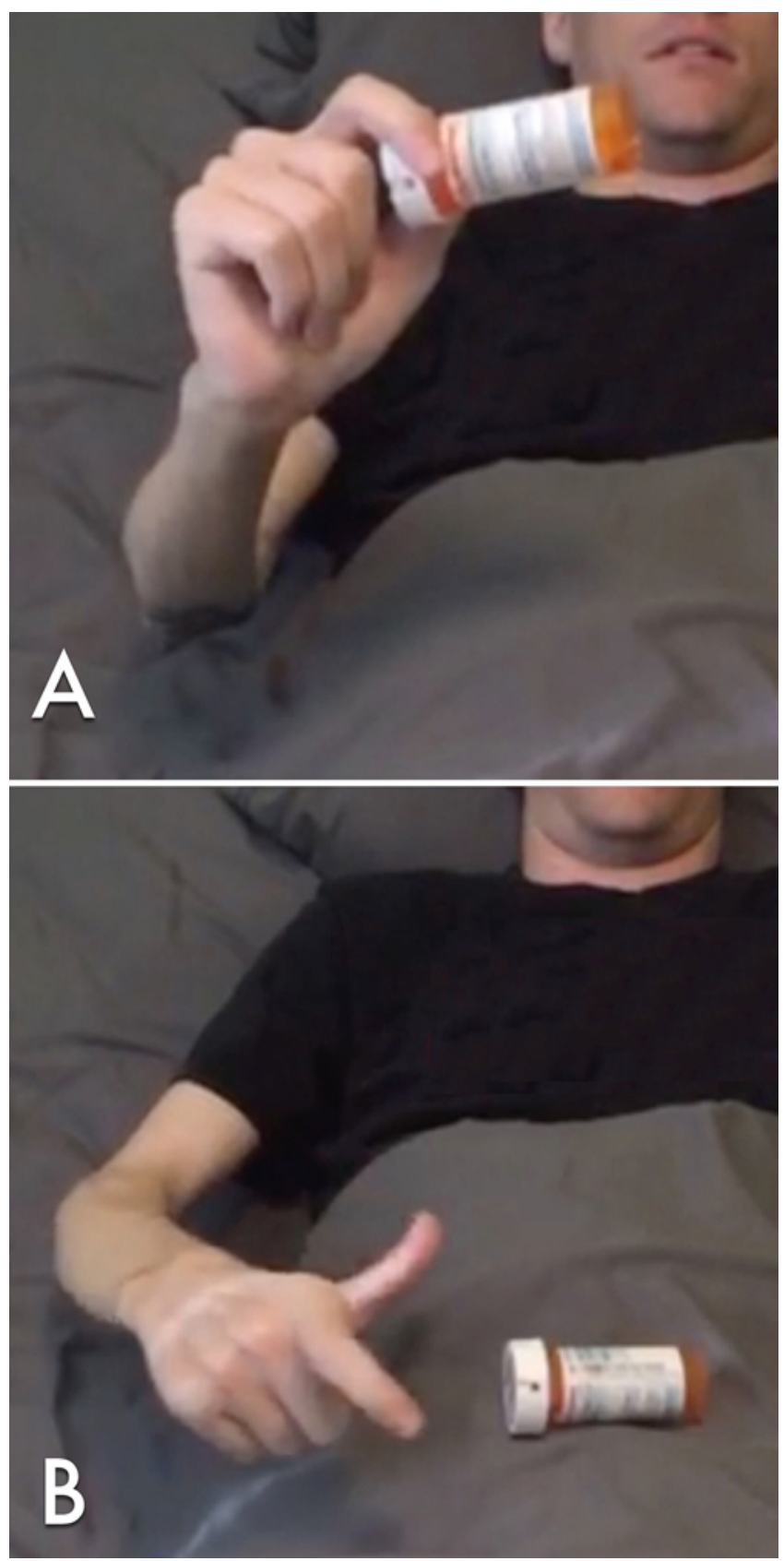

FIG. 9. Case 5. While nerve transfers are an effective means by which to recover function, a "hybrid" reconstruction using multiple techniques can often achieve a better ultimate outcome. After a number of years without finger function at all, this patient achieved effective grasp and release capabilities. This result was enhanced by means of thumb carpometacarpal fusion to precisely position its palmar abduction.

VIDEO 5. Case 5. A "hybrid" procedure, including nerve transfers, tendon transfers, and bony fixation, can often achieve a better result than any of these procedures alone. This patient, who had no finger movement for years after his cervical SCl, recovered effective finger and thumb extension by means of nerve transfer, finger flexion by means of a second nerve transfer, thumb flexion by means of a tendon transfer, and thumb palmar abduction positioning by means of thumb carpometacarpal fusion. Copyright Justin Brown. Published with permission. Click here to view. 


\section{Addressing Problematic Spasticity}

The clinical needs of these patients have also highlighted the problem of spasticity, particularly in motor-incomplete SCI patients. As such, the application of selective peripheral neurotomy to downgrade dysfunctional activity, while at the same time preserving motor control, may have its role in the same patient. Yet, the management of spasticity is often complex, with contractures and weakness occurring in various degrees. Thus, neurotomy alone is at times not sufficient to achieve the relaxation required. In such cases, tendon lengthening with or without a tendon transfer is required to balance forces across a joint.

When addressing primarily spastic patients-whether hemiplegic from stroke or TBI, or quadriparetic from SCI or TBI-it should be understood that spasticity often conceals neighboring muscles with functional control. While some details of the motor control of the limb can be determined through a detailed physical examination, much cannot. Multichannel functional electromyography (EMG) provides the best information regarding the underlying motor control: for example, which muscles are driven by passive stretching alone, which are continuously active, and which produce controlled activation (whether discretely or in a delayed fashion) can be identified (Fig. 10). ${ }^{10,17,26}$ Continuously active muscle groups that impair function may be best addressed with a neurectomy (complete severing of the nerve) or tenotomy (complete division of the tendon) in order to remove its contribution to the function of the limb. Those patients with present but poor activation and poor deactivation (and thus problematic spasticity) are candidates for selective peripheral neurotomy (partial severing of the nerve) or tendon lengthening in order to preserve its contribution to the limb while reducing its spastic and dysfunctional output. ${ }^{15,30}$ Finally, discrete motor control should be strengthened to augment its primary function or transferred to achieve a higher priority function. That transfer can be accomplished via either tendon transfer or nerve transfer. Whether the nerve or tendon transfer is better in a particular scenario is currently an area of ongoing research.

An excellent example of this approach is found in spastic "foot drop." For ambulatory but spastic patients, tibial neurotomy has been found to improve foot position and walking endurance. ${ }^{16,18,41}$ In this procedure, the branches of the tibial nerve that innervate the gastrocnemius, soleus, tibialis posterior, and toe flexors are trimmed (based upon their relative contribution to dysfunction as determined by functional EMG). This downgrades the drive for an equinovarus foot and allows the patient to return to therapy almost immediately. When some active dorsiflexion and eversion are present preoperatively, we often find that they become dramatically more effective postoperatively. In fact, some patients are able to graduate from their ankle-foot orthoses (AFOs). When excessive inversion does not correct, a split tibialis anterior tendon transfer can augment the effect of this neurotomy procedure by balancing the newly acquired dorsiflexion and prevent inversion. Following this intervention, the potential for graduation from the AFO is notably improved. ${ }^{47}$ See Illustrative Case 6.

Illustrative Case 6: Neurotomy for Stroke-Related Gait Impairment

Our team cared for a 36-year-old woman who suffered

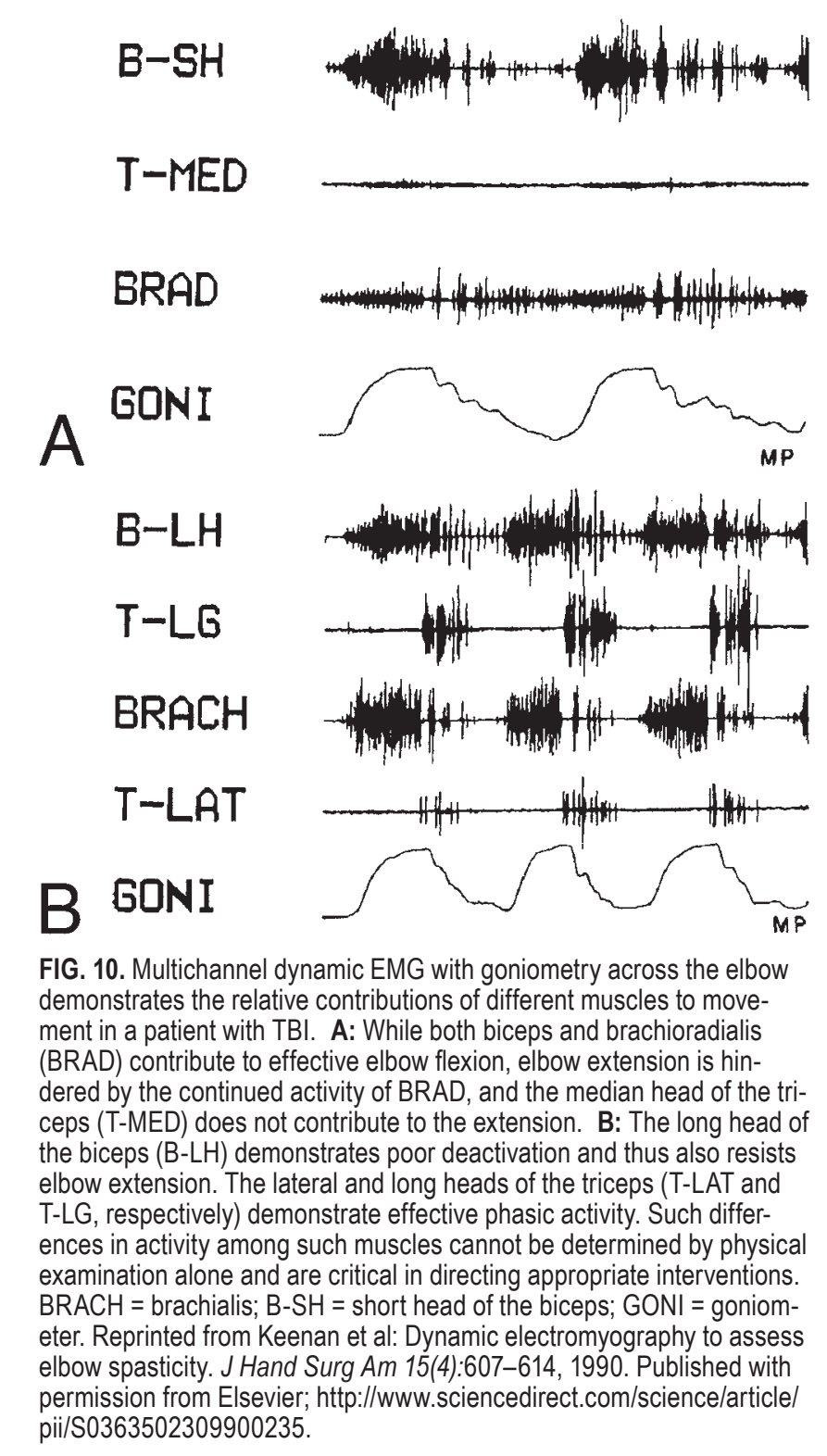

a brain hemorrhage and had undergone arteriovenous malformation (AVM) resection and clipping of an associated aneurysm in the Middle East several years prior to presentation. She was left with left hemiparesis and an equinovarus foot that required the use of an AFO brace for ambulation. She initially underwent similar tibial neurotomies, and while this provided notable relief of her toe flexion and plantar spasticity, she would progress back to inversion after several steps as her peroneal muscles fatigued. When this did not improve with extensive therapy, she underwent split anterior tibialis tendon transfer, which was successful in correcting this inversion (Fig. 11). See Video 6.

VIDEO 6. Case 6. After evacuation of an intracerebral hematoma and resection of an AVM, this patient was left with significant leftsided spasticity and gait dysfunction requiring the use of an AFO brace to ambulate. Even with this brace in place, her foot turns in fighting the corrected position. She initially underwent a tibial neu- 

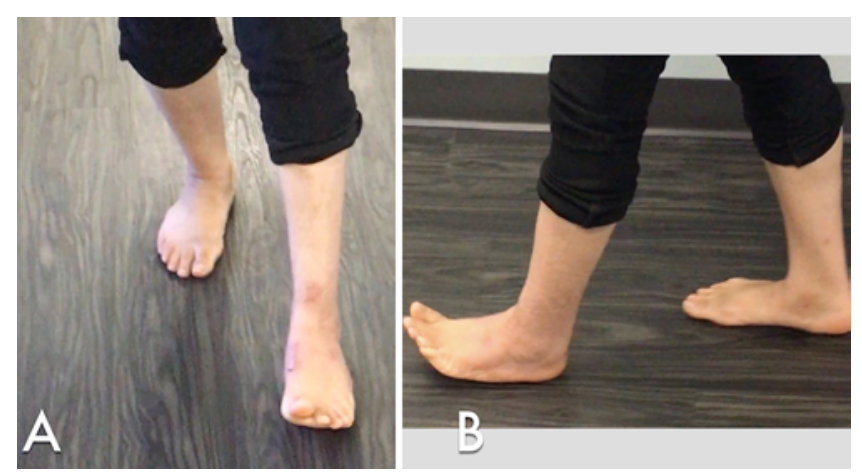

FIG. 11. Case 6. Our team cared for a 36-year-old woman who suffered a brain hemorrhage and had undergone AVM resection and clipping of an associated aneurysm in the Middle East several years prior to presentation. She was left with left hemiparesis and an equinovarus foot requiring the use of an AFO brace for ambulation. She initially underwent similar tibial neurotomies, and while this provided notable relief of her toe flexion and plantar spasticity, she would progress back to inversion after several steps as her peroneal muscles fatigued. When this did not improve with extensive therapy, she underwent split anterior tibialis tendon transfer, which was successful in correcting this inversion.

rotomy that improved dorsiflexion but did not result in effective eversion. She underwent a split tibialis anterior tendon transfer, and this enabled her to graduate from the brace and maintain a more functional ankle posture during gait. Copyright Justin Brown. Published with permission. Click here to view.

Another common scenario that is effectively addressed using these same concepts is found in spastic shoulder ad- duction and internal rotation. This dysfunction is driven by a combination of pectoralis, subscapularis, latissimus, and teres major overactivity working against the tonically inhibited teres minor and infraspinatus. If dynamic EMG demonstrates good volitionally controlled phasic activity in the external rotators, neurotomies of the nerve branches innervating the pectoralis major and subscapularis may be sufficient to restore balance across the shoulder. When the external rotators are not sufficiently active and the patient demonstrates effective (yet unopposed) control of the latissimus dorsi, a procedure to reroute latissimus dorsi insertion to the rotator cuff posteriorly in order to create external rotation may provide functional improvement. ${ }^{1}$

These same principles can be applied to the wrist, hand, knee, and elbow. Of note, the tendon transfer procedures used for total brachial plexus injuries tend to be the same that are used in these scenarios as well. Some examples of the procedural overlap among the numerous sources of paralysis are presented in Table 1.

\section{Looking Forward}

The interventions discussed above provide the foundation for the practice of restoring function to those suffering functional loss as a result of a neurological injury. Given the enormous amount of research that is ongoing nationally and internationally to develop biological and synthetic methods that restore function, these surgical options will quickly be augmented by a number of additional procedural resources. However, it is very unlikely that this foun-

TABLE 1. Sampling of reconstructive procedures and their relative utility in treating different paralysis sources involving upper- and/or lower-extremity impairments

\begin{tabular}{|c|c|c|c|c|c|c|}
\hline Intervention & $\begin{array}{l}\text { Nerve Root } \\
\text { Injury }\end{array}$ & $\begin{array}{l}\text { Total Brachial } \\
\text { Plexus Injury }\end{array}$ & $\begin{array}{c}\text { Partial Plexus/ } \\
\text { Peripheral Nerve Injury }\end{array}$ & $\begin{array}{l}\text { Complete } \\
\text { SCl }\end{array}$ & $\begin{array}{l}\text { Incomplete/ } \\
\text { Spastic SCl }\end{array}$ & $\begin{array}{c}\text { Hemiparesis/ } \\
\text { Hemiplegia }\end{array}$ \\
\hline \multicolumn{7}{|l|}{ Nerve-based procedure } \\
\hline Nerve graft & No & Yes & Yes & No & No & No \\
\hline Nerve transfer & Yes & Yes & Yes & Yes & Yes* & Yes $^{*}$ \\
\hline Neurotomy & No & No & No & Occasional & Yes & Yes \\
\hline \multicolumn{7}{|l|}{ Muscle/tendon-based procedure } \\
\hline \multicolumn{7}{|l|}{ Upper extremity } \\
\hline Tendon lengthening or release & Occasional & Occasional & Occasional & Yes & Yes & Yes \\
\hline Latissimus transfer & Yes & Yes & Occasional & Yes & Yes & Yes \\
\hline Trapezius transfer & Yes & Yes & Occasional & Yes & Yes & Yes \\
\hline Intrinsic reconstruction of the hand & Yes & Yes & Occasional & Occasional & Occasional & Yes \\
\hline \multicolumn{7}{|l|}{ Lower extremity } \\
\hline Split anterior tibial tendon transfer & Yes & No & No & Yes & Yes & Yes \\
\hline Tibialis posterior tendon transfer & Yes & No & Yes & No & No & No \\
\hline \multicolumn{7}{|l|}{ Bony fusion } \\
\hline Wrist fusion & Yes & Yes & Occasional & Yes & Yes & Yes \\
\hline Thumb carpometacarpal fusion & Yes & Yes & Occasional & Yes & Yes & Yes \\
\hline Glenohumeral arthrodesis & Occasional & Yes & Occasional & Yes & Occasional & Occasional \\
\hline \multicolumn{7}{|l|}{ Muscle transplantation } \\
\hline Free functional muscle transplant & Occasional & Yes & Occasional & Yes $^{*}$ & No & No \\
\hline
\end{tabular}

No = no role for this procedure in this clinical scenario; occasional = the procedure would be uncommon, but might be considered in specific cases; yes = there is a role for this procedure in this clinical scenario.

* Indicates a current area of investigation. Case reports have been published, but not yet accepted as a standard approach. 
dation will be replaced. For example, should success in SCI be achieved in consistently regenerating white matter tracts across a lesion, it remains highly unlikely that the technology would transform a patient with an ASIA Grade B injury into someone with deficit-free motor control. Most likely, formerly paralyzed patients would then improve into a category of impaired control and spasticity that would still require optimization by the previously described procedures. Similarly, neuroprosthetics would likely find their highest yield in patients without transferrable tendons or nerves, including C-3 SCI, amyotrophic lateral sclerosis, and locked-in syndrome. As this specialty matures, it may serve to push the goals of our basic research. For example, stem cell-based research that is aimed at converting ASIA Grade A SCI at C-5 into a ASIA Grade A SCI at C-7 becomes much less relevant because this can be safely accomplished with current surgical techniques and without the risks of losing additional function from direct spinal cord manipulation. Additionally, the opportunities for neuroprosthetics and exoskeleton technology will be better defined, as the boundaries where the surgical options end and the consideration of these alternatives should begin are further defined.

\section{Why Neurosurgeons?}

It has been questioned whether neurosurgeons are the appropriate specialists to manage these disorders. The same discussions have been held regarding certain pathologies of the cerebral vasculature, skull base, spine, and peripheral nerves. Other specialties, including radiology, otolaryngology, orthopedics, and plastic surgery, have competed for portions of these arenas. While specialists in plastic and reconstructive surgery, as well as orthopedics, have played a very important role in the development of this field, in the case of a paralysis practice neurosurgeons hold an important position for a number of reasons. First, we are the surgeons who best understand the pathologies that result in these paralyzing conditions and can best determine whether the original pathology has been adequately addressed and whether there may be future concerns related to such pathology; if they have not been appropriately addressed, we have the capacity to do so. In some cases, this may obviate the need for reconstruction. Second, while we overlap with other specialties in the ability to master many of the reconstructive procedures outlined above, additionally we are uniquely positioned to adopt more proximal interventions. To this end, in recent years reconstructive interventions that have migrated proximally include nerve root reimplantation ${ }^{9}$ and contralateral nerve root transfer via the prevertebral route, ${ }^{48}$ and clinical studies are already introducing the intraparenchymal injection of stem cells, ${ }^{12}$ neuromodulation with epidural stimulation, ${ }^{37}$ and braincomputer interfaces ${ }^{31}$ Finally, it is important that we as a specialty are fully equipped to address the consequences of the interventions that we regularly undertake. As such, a typical neurosurgery morbidity and mortality conference provides cases amenable to the interventions described in this communication.

We are not arguing that other disciplines should not be a part of such a program. Quite the contrary, these disorders can often benefit from input from specialists with differ- ent backgrounds, and a team approach is ideal. We would strongly assert, though, that the neurosurgeon should be a key player in this field. The goal of adopting these additional procedures is not to obviate the need for our plastic and orthopedic colleagues, but to be able to expand our practice to depend upon them to provide the procedures that are within the scope of their typical practices. This concept would apply to the practitioners of other specialties who want to take on this field as well. We should be willing to lean on our hand surgeon colleagues when proximal row carpectomy is required to optimize wrist position for improved grasp. We likewise would be wise to team up with a competent plastic surgeon when undertaking a free functional muscle transplant, as any microsurgerytrained plastic surgeon should be relatively proficient in tissue transplantation and will make a good teammate in this technically challenging endeavor. Similarly, at times these traumatic injuries result in notable heterotopic ossifications, joint deformities, and even tissue defects in the area to be reanimated. A neurosurgeon would be foolish to not call on their orthopedic and plastic surgery colleagues in these cases.

\section{Multidisciplinary Team Approach}

Therefore, while we believe that a properly trained reconstructive neurosurgeon would be central to such a discipline, ideally this practice would be approached using the "cancer center model." Surgery accounts for only a portion of the effort involved in a patient's recovery from a paralyzing injury and would not be optimally implemented in isolation. It would be optimal to approach patients with motor control impairments as part of a multidisciplinary team. Such a team might include specialists in physical medicine and rehabilitation, physical and occupational therapy, neurophysiology, neurology, radiology, and orthotics, as well as orthopedics and plastic surgery, who could all contribute their expertise in order to achieve optimal outcomes and ensure that all avenues for recovery have been considered.

The source injury would be defined by a review of the patient's history, prior interventions, and the findings provided by neuroradiology and neurophysiology. Once the source has been adequately addressed and its potential for progression has been minimized, elucidation of the primary function-limiting deficit would be undertaken. This would be primarily ascertained from the physical examinations of the physiatrists, therapists, and the surgeon, and supported by neurophysiological findings as described above. With the deficits and assets fully defined, the primary functional goals would be agreed upon by the team. Next, potential conservative interventions, including physical therapy, bracing, medications, and neurolytic options, would be reviewed. Finally, the available reconstructive options to achieve that goal would be presented and discussed. Psychological fitness to undergo major interventions would be provided by psychology. If the team agrees that the patient is a good candidate, preoperative considerations such as optimizing joint range of motion and strengthening donor muscles, for example, are determined. Similarly, a postoperative retraining regimen can be determined with physiatry and therapy, with input regarding the bracing needs provided by orthotics in concert 
with the surgical team. As a consequence, all members of the team are on board as reconstruction is pursued and the outcomes are more objectively assessed. When things do not go as planned, the team reviews the execution of the previously devised plans and troubleshoots to arrive at the best reconstructive plan for a given deficit.

\section{Training}

Given the above requirements, and in addition to recapturing the art of the complete neurological examination, subspecialty training in reconstructive neurosurgery must include developing mastery of extremity anatomy, both surgical and functional, as well as a solid understanding of neurophysiological principles and how these can be used to guide interventions. It is also useful to develop an understanding of the basics of the physical and occupational therapy principles involved in these cases and, finally, an understanding of the roles of medications and nonoperative interventions, including botulinum toxin, in managing these disabilities.

We strongly advocate for a joint neurophysiology clinic in which a decision tree is navigated to provide dynamic responses to new findings as they arise. This would involve a discussion that works through the algorithm of potential interventions as the investigation proceeds. It should be noted that the experience and interest of the neurophysiologist is critical, as classic electrodiagnostic studies are limited in answering the many questions required to direct these interventions. Indeed, most neurophysiologists are not trained to address the questions that are typically the focus of such a clinic. Even those who are technically competent and interested would be unlikely to guess how to approach the patient electrodiagnostically without direct communication in real time and a basic understanding of the management options.

Finally, the trainee should gain a thorough knowledge of all reconstructive options for the range of deficits encountered. Brachial plexus exploration and reconstruction strategies would be central. Nerve and tendon transfer options for median, radial, and ulnar nerve injuries affecting the forearm and hand; nerve, tendon transfer, and free muscle options for restoring biceps and triceps function; nerve and tendon transfer options for restoring shoulder function, including external rotation, flexion, abduction, and scapular stabilization; and tendon transfer options for foot and ankle dysfunction should all be mastered. With this foundation, developing the concepts for neurotomy, tendon lengthening, and release for spasticity reduction in each of these arenas becomes easily incorporated.

The physical examination, electrodiagnostic studies, and imaging form the foundation upon which we decide which patients will go on to make an acceptable spontaneous recovery without surgery, who will require surgery, and what surgery will be most effective to achieve the goal most critical to that patient. As such, there is a significant departure from much of what is focused on in a typical neurosurgical residency, and we believe that more than 6 months is required to master these concepts.

\section{Conclusions}

The number of weakness and paralysis cases generated at a single medical center is more than enough to keep a reconstructive neurosurgeon, or even a team of reconstructive surgeons, quite busy with a surgical neurorehabilitation practice. The field is ripe for development given the number of new interventions being brought forth, our current research programs, and the opportunity to combine the current state of the art of different domains into a comprehensive program. Successful incorporation of multiple techniques will lay an important foundation upon which to build future restorative procedures.

Reconstructive interventions that are not traditionally performed by neurosurgeons but augment functional recovery include tendon transfers, free functional muscle transplants, and, for spasticity, tendon lengthening. Occasionally, bony fusions are required to fixate a limb or digit in a more functionally optimal position when limited degrees of freedom remain to be optimized. Marrying these interventions with the rapidly expanding options in peripheral nerve transfer and reconstruction, as well as emerging neuromodulation and neuroprosthetic options, provides a robust repertoire with which to achieve a high degree of sophistication in the development of reconstructive strategies. Ideally, such a practice would take advantage of the numerous specialists within such a medical center that overlap in the treatment of such patients. We advocate for a cancer center model to arrive at the best outcome and facilitate open communication among the different specialists contributing to this care.

\section{Acknowledgments}

We would like to thank Dr. Madhawi Mitwalli for her critical assistance in manuscript and media preparation.

\section{References}

1. Al-Qattan MM: Latissimus dorsi transfer for external rotation weakness of the shoulder in obstetric brachial plexus palsy. J Hand Surg Br 28:487-490, 2003

2. Benzel EC, Larson SJ: Functional recovery after decompressive operation for thoracic and lumbar spine fractures. Neurosurgery 19:772-778, 1986

3. Bertelli JA, Ghizoni MF: Nerve transfers for elbow and finger extension reconstruction in midcervical spinal cord injuries. J Neurosurg 122:121-127, 2015

4. Brown JM: Nerve transfers in tetraplegia I: Background and technique. Surg Neurol Int 2:121, 2011

5. Brown JM: The reconstructive neurosurgery of spinal cord injury, in Dimitrijevic MR, Kakulas BA, McKay WB, et al (eds): Restorative Neurology of Spinal Cord Injury. New York: Oxford University Press, 2012

6. Brown JM, Shah MN, Mackinnon SE: Distal nerve transfers: a biology-based rationale. Neurosurg Focus 26(2):E12, 2009

7. Bryden AM, Wuolle KS, Murray PK, Peckham PH: Perceived outcomes and utilization of upper extremity surgical reconstruction in individuals with tetraplegia at model spinal cord injury systems. Spinal Cord 42:169-176, 2004

8. Cain SA, Gohritz A, Fridén J, van Zyl N: Review of upper extremity nerve transfer in cervical spinal cord injury. J Brachial Plex Peripher Nerve Inj 10:e34-e42, 2015

9. Carlstedt T, Anand P, Hallin R, Misra PV, Norén G, Seferlis $\mathrm{T}$ : Spinal nerve root repair and reimplantation of avulsed ventral roots into the spinal cord after brachial plexus injury. J Neurosurg 93 (2 Suppl):237-247, 2000

10. Chen CL, Wong MK, Chen HC, Cheng PT, Tang FT: Correlation of polyelectromyographic patterns and clinical upper 
motor neuron syndrome in hemiplegic stroke patients. Arch Phys Med Rehabil 81:869-875, 2000

11. Curry BP, Kalani MYS, Sonntag VKH: Lessons from a life: the journey of spinal neurosurgery in the United States, in Pinheiro-Franco JL, Vaccaro AR, Benzel EC, et al (eds): Advanced Concepts in Lumbar Degenerative Disk Disease. Berlin: Springer, 2016, pp 805-816

12. Curtis E, Gabel BC, Marsala M, Ciacci JD: 172 A phase I, open-label, single-site, safety study of human spinal cordderived neural stem cell transplantation for the treatment of chronic spinal cord injury. Neurosurgery 63 (Suppl 1):168169, 2016

13. Dasari VR, Veeravalli KK, Dinh DH: Mesenchymal stem cells in the treatment of spinal cord injuries: a review. World J Stem Cells 6:120-133, 2014

14. Dean SG, Poltawski L, Forster A, Taylor RS, Spencer A, James M, et al: Community-based rehabilitation training after stroke: protocol of a pilot randomised controlled trial (ReTrain). BMJ Open 6:e012375, 2016

15. Decq P: [Peripheral neurotomies for the treatment of focal spasticity of the limbs.] Neurochirurgie 49:293-305, 2003 (Fr)

16. Deltombe T, Gustin T: Selective tibial neurotomy in the treatment of spastic equinovarus foot in hemiplegic patients: a 2-year longitudinal follow-up of 30 cases. Arch Phys Med Rehabil 91:1025-1030, 2010

17. Esquenazi A, Mayer NH: Instrumented assessment of muscle overactivity and spasticity with dynamic polyelectromyographic and motion analysis for treatment planning. Am J Phys Med Rehabil 83 (10 Suppl):S19-S29, 2004

18. Fève A, Decq P, Filipetti P, Verroust J, Harf A, N'Guyen JP, et al: Physiological effects of selective tibial neurotomy on lower limb spasticity. J Neurol Neurosurg Psychiatry 63:575-578, 1997

19. Fridén J, Gohritz A: Tetraplegia management update. J Hand Surg Am 40:2489-2500, 2015

20. Girardi FP, Cammisa FP Jr, Huang RC, Parvataneni HK, Tsairis P: Improvement of preoperative foot drop after lumbar surgery. J Spinal Disord Tech 15:490-494, 2002

21. Guigui P, Benoist M, Delecourt C, Delhoume J, Deburge A: Motor deficit in lumbar spinal stenosis: a retrospective study of a series of 50 patients. J Spinal Disord 11:283-288, 1998

22. Harbaugh RE, Agarwal A: Training residents in endovascular neurosurgery. Neurosurgery 59 (5 Suppl 3):S277-S281, S3-S13, 2006

23. Hentz VR, Narakas A: The results of microneurosurgical reconstruction in complete brachial plexus palsy. Assessing outcome and predicting results. Orthop Clin North Am 19:107-114, 1988

24. Hillier SL, Sharpe MH, Metzer J: Outcomes 5 years post-traumatic brain injury (with further reference to neurophysical impairment and disability). Brain Inj 11:661675, 1997

25. Kaiser R, Waldauf P, Haninec P: Types and severity of operated supraclavicular brachial plexus injuries caused by traffic accidents. Acta Neurochir (Wien) 154:1293-1297, 2012

26. Keenan MA, Fuller DA, Whyte J, Mayer N, Esquenazi A, Fidler-Sheppard R: The influence of dynamic polyelectromyography in formulating a surgical plan in treatment of spastic elbow flexion deformity. Arch Phys Med Rehabil 84:291-296, 2003

27. Kirshblum S, Millis S, McKinley W, Tulsky D: Late neurologic recovery after traumatic spinal cord injury. Arch Phys Med Rehabil 85:1811-1817, 2004

28. Kreisel SH, Bazner H, Hennerici MG: Pathophysiology of stroke rehabilitation: temporal aspects of neuro-functional recovery. Cerebrovasc Dis 21:6-17, 2006

29. Langlois JA, Rutland-Brown W, Thomas KE: Traumatic Brain Injury in the United States: Emergency Depart- ment Visits, Hospitalizations, and Deaths. Atlanta: Centers for Disease Control and Prevention, 2004

30. Lazorthes Y, Sol JC, Sallerin B, Verdié JC: The surgical management of spasticity. Eur J Neurol 9 (Suppl 1):35-61, 2002

31. Leuthardt EC, Schalk G, Moran D, Ojemann JG: The emerging world of motor neuroprosthetics: a neurosurgical perspective. Neurosurgery 59:1-14, 2006

32. Li J, Lepski G: Cell transplantation for spinal cord injury: a systematic review. BioMed Res Int 2013:786475, 2013

33. Maarrawi J, Mertens P, Luaute J, Vial C, Chardonnet N, Cosson M, et al: Long-term functional results of selective peripheral neurotomy for the treatment of spastic upper limb: prospective study in 31 patients. J Neurosurg 104:215-225, 2006

34. Mahomed NN, Barrett J, Katz JN, Baron JA, Wright J, Losina E: Epidemiology of total knee replacement in the United States Medicare population. J Bone Joint Surg Am 87:1222-1228, 2005

35. McGrath PD, Wennberg DE, Dickens JD Jr, Siewers AE, Lucas FL, Malenka DJ, et al: Relation between operator and hospital volume and outcomes following percutaneous coronary interventions in the era of the coronary stent. JAMA 284:3139-3144, 2000

36. Minassian K, Hofstoetter U, Tansey K, Mayr W: Neuromodulation of lower limb motor control in restorative neurology. Clin Neurol Neurosurg 114:489-497, 2012

37. Minassian K, McKay WB, Binder H, Hofstoetter US: Targeting lumbar spinal neural circuitry by epidural stimulation to restore motor function after spinal cord injury. Neurotherapeutics 13:284-294, 2016

38. Reier PJ, Lane MA, Hall ED, Teng YD, Howland DR: Translational spinal cord injury research: preclinical guidelines and challenges. Handb Clin Neurol 109:411-433, 2012

39. Shanechi MM, Hu RC, Williams ZM: A cortical-spinal prosthesis for targeted limb movement in paralysed primate avatars. Nat Commun 5:3237, 2014

40. Sindou M, Abdennebi B, Sharkey P: Microsurgical selective procedures in peripheral nerves and the posterior root-spinal cord junction for spasticity. Appl Neurophysiol 48:97-104, 1985

41. Sindou M, Mertens P: Selective neurotomy of the tibial nerve for treatment of the spastic foot. Neurosurgery 23:738-744, 1988

42. Sindou M, Mertens P, Jeanmonod D: Microsurgical ablative procedures in the peripheral nerves and dorsal root entry zone for relief of focal spasticity in the limbs. Stereotact Funct Neurosurg 54-55:140-146, 1990

43. Sindou MP, Simon F, Mertens P, Decq P: Selective peripheral neurotomy (SPN) for spasticity in childhood. Childs Nerv Syst 23:957-970, 2007

44. Stauffer ES: Diagnosis and prognosis of acute cervical spinal cord injury. Clin Orthop Relat Res (112):9-15, 1975

45. Tetzlaff W, Okon EB, Karimi-Abdolrezaee S, Hill CE, Sparling JS, Plemel JR, et al: A systematic review of cellular transplantation therapies for spinal cord injury. J Neurotrauma 28:1611-1682, 2011

46. van Heek NT, Kuhlmann KF, Scholten RJ, de Castro SM, Busch OR, van Gulik TM, et al: Hospital volume and mortality after pancreatic resection: a systematic review and an evaluation of intervention in the Netherlands. Ann Surg 242:781-790, 2005

47. Vogt JC: Split anterior tibial transfer for spastic equinovarus foot deformity: retrospective study of 73 operated feet. J Foot Ankle Surg 37:2-7, 78, 1998

48. Wang S, Li P, Xue Y, Yiu H, Li YC, Wang H: Contralateral C7 nerve transfer with direct coaptation to restore lower trunk function after traumatic brachial plexus avulsion. J Bone Joint Surg Am 95:821-827, S1-S2, 2013

49. Wenger N, Moraud EM, Gandar J, Musienko P, Capogrosso 
M, Baud L, et al: Spatiotemporal neuromodulation therapies engaging muscle synergies improve motor control after spinal cord injury. Nat Med 22:138-145, 2016

50. Wyndaele M, Wyndaele JJ: Incidence, prevalence and epidemiology of spinal cord injury: what learns a worldwide literature survey? Spinal Cord 44:523-529, 2006

51. Yablon IG, Palumbo M, Spatz E, Mortara R, Reed J, Ordia $\mathrm{J}$ : Nerve root recovery in complete injuries of the cervical spine. Spine (Phila Pa 1976) 16 (10 Suppl):S518-S521, 1991

\section{Disclosures}

The authors report no conflict of interest concerning the materials or methods used in this study or the findings specified in this paper.

\section{Author Contributions}

Conception and design: Brown, Mandeville. Acquisition of data: Brown. Analysis and interpretation of data: Brown. Drafting the article: Brown. Critically revising the article: all authors.
Reviewed submitted version of manuscript: Brown, Carter. Approved the final version of the manuscript on behalf of all authors: Brown. Administrative/technical/material support: Mahan, Mandeville.

\section{Supplemental Information \\ Videos}

Video 1. https://vimeo.com/216831749.

Video 2. https://vimeo.com/216831882.

Video 3. https://vimeo.com/216831963.

Video 4. https://vimeo.com/216832069.

Video 5. https://vimeo.com/216832168.

Video 6. https://vimeo.com/216832266.

Video Abstract. https://vimeo.com/220787253.

\section{Correspondence}

Justin M. Brown, Department of Neurosurgery, UCSD, 4510 Executive Dr., Ste. 325, MC 0973, San Diego, CA 92121. email: jmbrown@ucsd.edu. 